\title{
Updated Gestational Age Specific Birthweight Reference of Hong Kong Chinese Newborns and Comparison with Local and International Growth Charts
}

\author{
Irene W. Y. Lok, Meliza C. W. Kong, William W. K. To* \\ Department of Obstetrics \& Gynaecology, United Christian Hospital, Hong Kong, China \\ Email: happyah2@hotmail.com, kcw305@ha.org.hk, *towkw@ha.org.hk
}

How to cite this paper: Lok, I.W.K., Kong, M.C.W. and To, W.W.K. (2021) Updated Gestational Age Specific Birthweight Reference of Hong Kong Chinese Newborns and Comparison with Local and International Growth Charts. Open Journal of Obstetrics and Gynecology, 11, 940-954. https://doi.org/10.4236/ojog.2021.118090

Received: July 14, 2021

Accepted: August 3, 2021

Published: August 6, 2021

Copyright $\odot 2021$ by author(s) and Scientific Research Publishing Inc. This work is licensed under the Creative Commons Attribution International License (CC BY 4.0).

http://creativecommons.org/licenses/by/4.0/

(c) (i) Open Access

\begin{abstract}
Background: Different gestational age specific birthweight reference charts have been produced for different populations and ethnic groups over different time periods, mostly based on birthweight data. This study aims to update birthweight references for Hong Kong (HK) Chinese newborns to provide norms for identification of small and large for gestational age (SGA and LGA) fetuses, and to verify whether there are significant differences compared to previously published local reference charts, as well as to other southern Chinese and international data. Methods: All singleton Chinese livebirths delivered in United Christian Hospital from 2012 to 2017 were retrospectively included. The smoothed birthweight centiles at each gestation were computed. The birthweight centiles were then compared with other reference charts. Results: A total of 25,508 livebirths between 24 and 42 completed weeks of gestation were enrolled in the final analysis. The mean birthweights of our cohort were largely similar to previous studies at each gestation, but the 10th and 90th centile ranges differed significantly, so that the proportion of babies that would be classified as SGA or LGA varied widely using cut-offs from different studies. Older local studies tend to under-estimate, while the international growth charts would over-estimate the proportion of SGA babies. Conclusions: Updating fetal growth curve references based on local data is essential to establish more precise definitions of SGA and LGA babies in clinical management. The use of international growth charts in our population may not be appropriate and requires further validation.
\end{abstract}

\section{Keywords}

Birthweight, Intrauterine Growth, Percentile, Hong Kong 


\section{Introduction}

Birthweight is an important marker to reflect the intrauterine growth environment of neonates as well as a critical determining factor of perinatal morbidity and mortality, and has implications for both short as well as long term outcome of these babies. While the direct associations between absolute birthweight and perinatal well-being are obvious [1] [2], it is of predominate importance to classify birthweight in accordance with gestation to identify small or large for gestational age infants. Small for gestational age (SGA) infants are likely to be growth restricted and have an increased risk of perinatal complications such as transient tachypnoea of the newborn, hypothermia, symptomatic hypoglycaemia and other perinatal morbidities [3]. Large for gestational age (LGA) infants are more prone to birth trauma, perinatal asphyxia, shoulder dystocia, and even perinatal death [4], with the incidence of adverse outcomes rising sharply with increasing birthweight over $4000 \mathrm{~g}$ [5].

The classification into appropriate for gestational age, LGA or SGA, has traditionally been defined using centile charts of birthweight at different gestational ages. Intrauterine growth percentiles representing Caucasian infants were used all over the world since it was developed by Lubchenco et al. in 1963 [6]. Fetal growth was known to vary with ethnicity, and ethnicity specific birthweight distributions were shown to predict neonatal morbidity better than the population-based birthweight [7] [8] [9]. Different countries such as the United Kingdom [10] [11] [12], the United States [13], Europe [14] [15], or Asia [16] [17] had previously published their specific birthweight standards. Wen et al. reported that the mean birthweight was lower in Chinese infants compared with Caucasian infants [18] and national birthweight reference percentiles for Chinese have also been published recently [19]. Moreover, different parts of China [20] [21] as well as Taiwan [22], all being ethnically Chinese, have their own birthweight references. Local birthweight reference in Hong Kong Chinese published in literature could be dated back as early to 1970s [23]. Since then, review and comparison of birthweight were made in 1980s by different authors [24] [25] [26] [27]. One such study compared the gestational age specific birthweight of Hong Kong Chinese in a cohort from 1998 to 2001 to his previous 1982-1986 cohort and was able to demonstrate a significant trend of increasing birthweight [27], indicating the need to update such birthweight charts from time to time to cater for possible secular changes. In this study, we aim to construct an updated gestational age specific birthweight reference of Hong Kong Chinese newborns using data within the past 10 years, and to compare it with the previous published local studies in the past five decades, with recent studies conducted in southern China [19] [20] and Taiwan [22], as well as with current prospective ultrasound derived growth references from international studies [28] [29]. The primary purpose is to provide updated norms for identification of small and large for gestational age fetuses for obstetric management. 


\section{Materials and Methods}

Delivery data in United Christian Hospital (UCH) from the calendar years of 2012 to 2017 were retrospectively extracted from the hospital electronic obstetrics clinical information system database. $\mathrm{UCH}$ is a regional tertiary referral obstetric centre, serving the Kowloon East district of Hong Kong, with an annual delivery rate of around 4200 to 5000 over the study period. All singleton livebirths of gestation $>24$ completed weeks and $\leq 42$ completed weeks who were of Chinese origin were included in the analysis. Multiple pregnancies, stillbirths, non-Chinese ethnicity and neonates with major congenital malformations or chromosomal abnormalities were excluded. Neonates born from mothers with medical conditions or common pregnancy complications such as hypertensive disorders or gestational diabetes mellitus were not excluded, in order to construct an intrauterine growth reference that would comprehensively include various confounding factors that would affect fetal growth. Babies were weighted naked immediately after birth by labour ward midwifes using electronic scales (SECA) to the nearest gram. Gestational age in completed weeks of pregnancy was determined based on the best obstetrical estimate, calculated from the last menstrual period and matched with first trimester dating ultrasound during Down syndrome screening in the majority of cases.

The study was approved by the local Research Ethics Review Board from the Kowloon East Cluster. The Statistical Package for Social Sciences (SPSS) for Windows 23 package was used for data entry and analysis. The 3rd, 5th, 10th, median, 90th, 95th and 97th centiles of birthweight at each gestation were computed for all included neonates. The birthweight data from both sexes were combined in this study. Similar centile charts were derived from previously published Hong Kong data based on retrospective birthweight data [23] [24] [25] [26] [27], as well from three other large population studies published within the past 2 decades [19] [20] [22]. The current cohort was further compared with two international fetal growth charts based on prospective ultrasonographic estimations of fetal growth and weight namely the INTERGROWTH-21 [28] and World health Organization chart [29]. Birthweights $<10$ th centile for its gestational age were classified as SGA, and those $>90$ th centile for its gestational age as LGA. The mean birthweights of the different local studies at various gestations were compared using ANOVA with post hoc t-tests. The birthweight data in present cohort was then reclassified as SGA and LGA according to the birthweight centiles in the other studies as mentioned. The percentage of pregnancies in our study classified as SGA and LGA using birthweight centiles of different studies were then compared.

\section{Results}

The birthweight data of a total of 25,508 singleton livebirths delivered in the UCH between 24 completed weeks and 42 completed weeks of gestation within the 6-year study period from 2012 to 2017 were used to construct the gestational 
age specific smoothed birthweight centiles. Over $96 \%$ of pregnancies included in the analysis had early ultrasound for dating during early gestation or at Down syndrome screening, while the rest had morphology scans or indicated scans within the second trimester to confirm their dates. As the sample size of livebirths delivered at or before 24 weeks was too small for reliable estimation of weight centiles, these were not included for the final analysis. Due to our routine protocol for inducing post-term pregnancies from 42 completed weeks, all were delivered before 42 completed weeks. Table 1 showed the median birthweight and smoothed centiles from 24 to 42 completed gestational weeks. Birthweight distribution within all gestational weeks followed a largely normal distribution. The mean birthweights across each gestational week were significantly different between the current cohort and the different Hong Kong studies (ANOVA $\mathrm{p}<$ 0.001). Post-hoc comparison of the current cohort at different gestations with the 5 local individual datasets showed statistically significant differences across almost all gestations. In particular, there were significant differences with all the studies between term gestations of 37 - 41 weeks except the Rogers study (Table 2).

The median birthweight and the 10th and 90th centile range at each gestational week amongst the different datasets also differed significantly between the

Table 1. Median birthweight and smoothed centiles at various gestations in $\mathrm{UCH}$ cohort.

\begin{tabular}{|c|c|c|c|c|c|c|c|c|}
\hline $\begin{array}{c}\text { Gestational } \\
\text { weeks }\end{array}$ & $\mathrm{n}$ & $3^{\text {rd }}$ Centile & $5^{\text {th }}$ centile & $\begin{array}{c}10^{\text {th }} \\
\text { centile }\end{array}$ & Median & $90^{\text {th }}$ Centile & $95^{\text {th }}$ centile & $97^{\text {th }}$ centile \\
\hline 25 & 14 & & & 650 & 765 & 867 & & \\
\hline 26 & 28 & 615 & 720 & 730 & 924 & 995 & 1020 & 1100 \\
\hline 27 & 18 & & 865 & 870 & 1005 & 1180 & 1200 & \\
\hline 28 & 18 & & 815 & 830 & 1153 & 1320 & 1335 & \\
\hline 29 & 23 & & 855 & 960 & 1240 & 1580 & 1665 & \\
\hline 30 & 40 & 844 & 948 & 1015 & 1400 & 1625 & 1644 & 1715 \\
\hline 31 & 62 & 990 & 1065 & 1140 & 1598 & 1790 & 1842 & 1905 \\
\hline 32 & 75 & 1100 & 1152 & 1250 & 1769 & 2125 & 2200 & 2245 \\
\hline 33 & 126 & 1271 & 1310 & 1570 & 2026 & 2470 & 2522 & 2542 \\
\hline 34 & 156 & 1430 & 1520 & 1650 & 2205 & 2570 & 2715 & 2765 \\
\hline 35 & 323 & 1715 & 1790 & 1910 & 2430 & 2775 & 2875 & 2925 \\
\hline 36 & 606 & 1895 & 2030 & 2202 & 2660 & 3125 & 3315 & 3456 \\
\hline 37 & 1615 & 2145 & 2220 & 2370 & 2847 & 3315 & 3495 & 3592 \\
\hline 38 & 6514 & 2440 & 2525 & 2643 & 3080 & 3570 & 37183 & 3815 \\
\hline 39 & 7105 & 2590 & 2665 & 2775 & 3195 & 3665 & 3810 & 3910 \\
\hline 40 & 5888 & 2685 & 2765 & 2880 & 3315 & 3810 & 3961 & 4070 \\
\hline 41 & 2573 & 2760 & 2832 & 2970 & 3415 & 3920 & 4088 & 4230 \\
\hline 42 & 24 & & 2750 & 2760 & 3538 & 3805 & 3820 & \\
\hline
\end{tabular}


Table 2. Comparison of mean birthweight at various gestations for different Hong Kong studies.

\begin{tabular}{|c|c|c|c|c|c|c|c|}
\hline $\begin{array}{c}\text { Gestational } \\
\text { weeks }\end{array}$ & $\mathrm{UCH}$ & Ip & Woo & Rogers & Fok 1987 & Fok $2003^{\#}$ & $\begin{array}{c}\text { ANOVA } \\
\text { p-value }\end{array}$ \\
\hline 25 & $\begin{array}{c}N=14 \\
768(80)\end{array}$ & & & & & $\begin{array}{c}\mathrm{N}=32 \\
780(125)\end{array}$ & 0.68 \\
\hline 26 & $\begin{array}{c}\mathrm{N}=28 \\
903(105)\end{array}$ & & & & & $\begin{array}{c}N=23 \\
840(97)\end{array}$ & 0.027 \\
\hline 27 & $\begin{array}{c}\mathrm{N}=18 \\
1037(139)\end{array}$ & & & & $\begin{array}{c}N=20 \\
965(148)\end{array}$ & $\begin{array}{c}N=37 \\
1020(180)\end{array}$ & 0.08 \\
\hline 28 & $\begin{array}{c}N=18 \\
1127(196)\end{array}$ & $\begin{array}{c}N=13 \\
1681(640)^{*}\end{array}$ & $\begin{array}{c}N=23 \\
1106(186)\end{array}$ & & $\begin{array}{c}\mathrm{N}=30 \\
1095(157)\end{array}$ & $\begin{array}{c}\mathrm{N}=46 \\
1130(170)\end{array}$ & $<0.001$ \\
\hline 29 & $\begin{array}{c}N=23 \\
1270(231)\end{array}$ & $\begin{array}{c}N=25 \\
1530(563)^{a}\end{array}$ & $\begin{array}{c}\mathrm{N}=21 \\
1253(195)\end{array}$ & & $\begin{array}{c}\mathrm{N}=45 \\
1239(210)\end{array}$ & $\begin{array}{c}\mathrm{N}=62 \\
1260(178)\end{array}$ & $<0.001$ \\
\hline 30 & $\begin{array}{c}N=40 \\
1364(238)\end{array}$ & $\begin{array}{c}N=43 \\
1938(708)^{*}\end{array}$ & $\begin{array}{c}\mathrm{N}=38 \\
1418(242)\end{array}$ & & $\begin{array}{c}N=41 \\
1405(197)\end{array}$ & $\begin{array}{c}\mathrm{N}=55 \\
1470(249)\end{array}$ & $<0.001$ \\
\hline 31 & $\begin{array}{c}\mathrm{N}=62 \\
1554(240)\end{array}$ & $\begin{array}{c}N=41 \\
2170(747)^{*}\end{array}$ & $\begin{array}{c}N=37 \\
1607(274)\end{array}$ & $\begin{array}{c}N=20 \\
2409(631)^{\star}\end{array}$ & $\begin{array}{c}N=52 \\
1598(208)\end{array}$ & $\begin{array}{c}N=66 \\
1560(280)\end{array}$ & $<0.001$ \\
\hline 32 & $\begin{array}{c}N=75 \\
1719(319)\end{array}$ & $\begin{array}{c}N=75 \\
2285(624)^{*}\end{array}$ & $\begin{array}{c}N=76 \\
1810(240)\end{array}$ & $\begin{array}{c}N=30 \\
2322(817)^{*}\end{array}$ & $\begin{array}{c}N=88 \\
1798(196)\end{array}$ & $\begin{array}{c}\mathrm{N}=81 \\
1800(384)\end{array}$ & $<0.001$ \\
\hline 33 & $\begin{array}{c}N=126 \\
2017(331)\end{array}$ & $\begin{array}{c}\mathrm{N}=100 \\
2406(596)^{*}\end{array}$ & $\begin{array}{c}\mathrm{N}=81 \\
1964(253)\end{array}$ & $\begin{array}{c}N=33 \\
2365(541)^{*}\end{array}$ & $\begin{array}{c}\mathrm{N}=97 \\
1975(217)\end{array}$ & $\begin{array}{c}N=154 \\
1930(354)\end{array}$ & $<0.001$ \\
\hline 34 & $\begin{array}{c}N=156 \\
2162(358)\end{array}$ & $\begin{array}{c}N=168 \\
2570(510)^{*}\end{array}$ & $\begin{array}{c}N=141 \\
2145(321)\end{array}$ & $\begin{array}{c}N=49 \\
2386(571)^{b}\end{array}$ & $\begin{array}{c}N=125 \\
2128(247)\end{array}$ & $\begin{array}{c}N=211 \\
2224(360)\end{array}$ & $<0.001$ \\
\hline 35 & $\begin{array}{c}N=323 \\
2396(329)\end{array}$ & $\begin{array}{c}\mathrm{N}=290 \\
2714(534)^{*}\end{array}$ & $\begin{array}{c}N=131 \\
2429(355)\end{array}$ & $\begin{array}{c}N=88 \\
2652(425)^{*}\end{array}$ & $\begin{array}{c}N=154 \\
2368(294)\end{array}$ & $\begin{array}{c}N=281 \\
2330(435)\end{array}$ & $<0.001$ \\
\hline 36 & $\begin{array}{c}N=606 \\
2661(377)\end{array}$ & $\begin{array}{c}\mathrm{N}=530 \\
2825(490)^{*}\end{array}$ & $\begin{array}{c}\mathrm{N}=321 \\
2671(404)\end{array}$ & $\begin{array}{c}\mathrm{N}=219 \\
2852(480)^{*}\end{array}$ & $\begin{array}{c}N=174 \\
2620(350)\end{array}$ & $\begin{array}{c}N=486 \\
2770(405)^{c}\end{array}$ & $<0.001$ \\
\hline 37 & $\begin{array}{c}\mathrm{N}=1915 \\
2854(375)\end{array}$ & $\begin{array}{c}N=914 \\
2889(417)\end{array}$ & $\begin{array}{c}N=766 \\
2918(397)^{*}\end{array}$ & $\begin{array}{c}N=496 \\
2985(423)^{*}\end{array}$ & $\begin{array}{c}N=416 \\
2830(376)\end{array}$ & $\begin{array}{c}N=783 \\
2990(409)\end{array}$ & $<0.001$ \\
\hline 38 & $\begin{array}{c}N=6514 \\
3096(367)\end{array}$ & $\begin{array}{c}N=2114 \\
2954(398)^{*}\end{array}$ & $\begin{array}{c}N=2208 \\
3030(382)^{*}\end{array}$ & $\begin{array}{c}N=1155 \\
3114(381)\end{array}$ & $\begin{array}{c}\mathrm{N}=938 \\
3025(342)^{*}\end{array}$ & $\begin{array}{c}N=1926 \\
3110(387)^{*}\end{array}$ & $<0.001$ \\
\hline 39 & $\begin{array}{c}N=7105 \\
3213(352)\end{array}$ & $\begin{array}{c}N=3658 \\
3048(376)^{*}\end{array}$ & $\begin{array}{c}N=3730 \\
3157(362)^{*}\end{array}$ & $\begin{array}{c}N=2020 \\
3202(391)\end{array}$ & $\begin{array}{c}N=1926 \\
3112(315)^{*}\end{array}$ & $\begin{array}{c}\mathrm{N}=2522 \\
3245(375)\end{array}$ & $<0.001$ \\
\hline 40 & $\begin{array}{c}\mathrm{N}=5888 \\
3332(368))\end{array}$ & $\begin{array}{c}N=3969 \\
3130(385)^{*}\end{array}$ & $\begin{array}{c}\mathrm{N}=5004 \\
3237(366)^{\star}\end{array}$ & $\begin{array}{c}N=2311 \\
3305(383)\end{array}$ & $\begin{array}{c}N=2145 \\
3192(322)^{*}\end{array}$ & $\begin{array}{c}N=2277 \\
3347(390)^{*}\end{array}$ & $<0.001$ \\
\hline 41 & $\begin{array}{c}N=2573 \\
3436(384)\end{array}$ & $\begin{array}{c}N=2572 \\
3169(393)^{*}\end{array}$ & $\begin{array}{c}N=2145 \\
3316(385)^{\star}\end{array}$ & $\begin{array}{c}N=1536 \\
3381(396)^{*}\end{array}$ & $\begin{array}{c}\mathrm{N}=1442 \\
3227(331)^{*}\end{array}$ & $\begin{array}{c}N=1049 \\
3430(404)^{*}\end{array}$ & $<0.001$ \\
\hline 42 & $\begin{array}{c}\mathrm{N}=24 \\
3394(428)\end{array}$ & $\begin{array}{c}N=1329 \\
3197(405)\end{array}$ & $\begin{array}{c}\mathrm{N}=1093 \\
3334(386)\end{array}$ & $\begin{array}{c}\mathrm{N}=801 \\
3401(419)^{\star}\end{array}$ & $\begin{array}{c}\mathrm{N}=752 \\
3265(341)\end{array}$ & $\begin{array}{c}\mathrm{N}=207 \\
3475(415)\end{array}$ & $<0.001$ \\
\hline
\end{tabular}

${ }^{*}$ p-value by post-hoc $\mathrm{t}$ test: ${ }^{*} \leq 0.001$ (shaded boxes); $\mathrm{a}=0.02 ; \mathrm{b}=0.007 ; \mathrm{c}=0.01$; ${ }^{*}$ mean birthweight values and standard deviations induced from summation of male/female newborns from primiparous and multiparous births in the original study.

different studies (Figure 1). Very wide inter-centile ranges between the $10^{\text {th }}$ and $90^{\text {th }}$ centile could be seen in the Ip [23] and Rogers [25] studies, the former being data collected in the early seventies when ultrasound for dating was not yet 


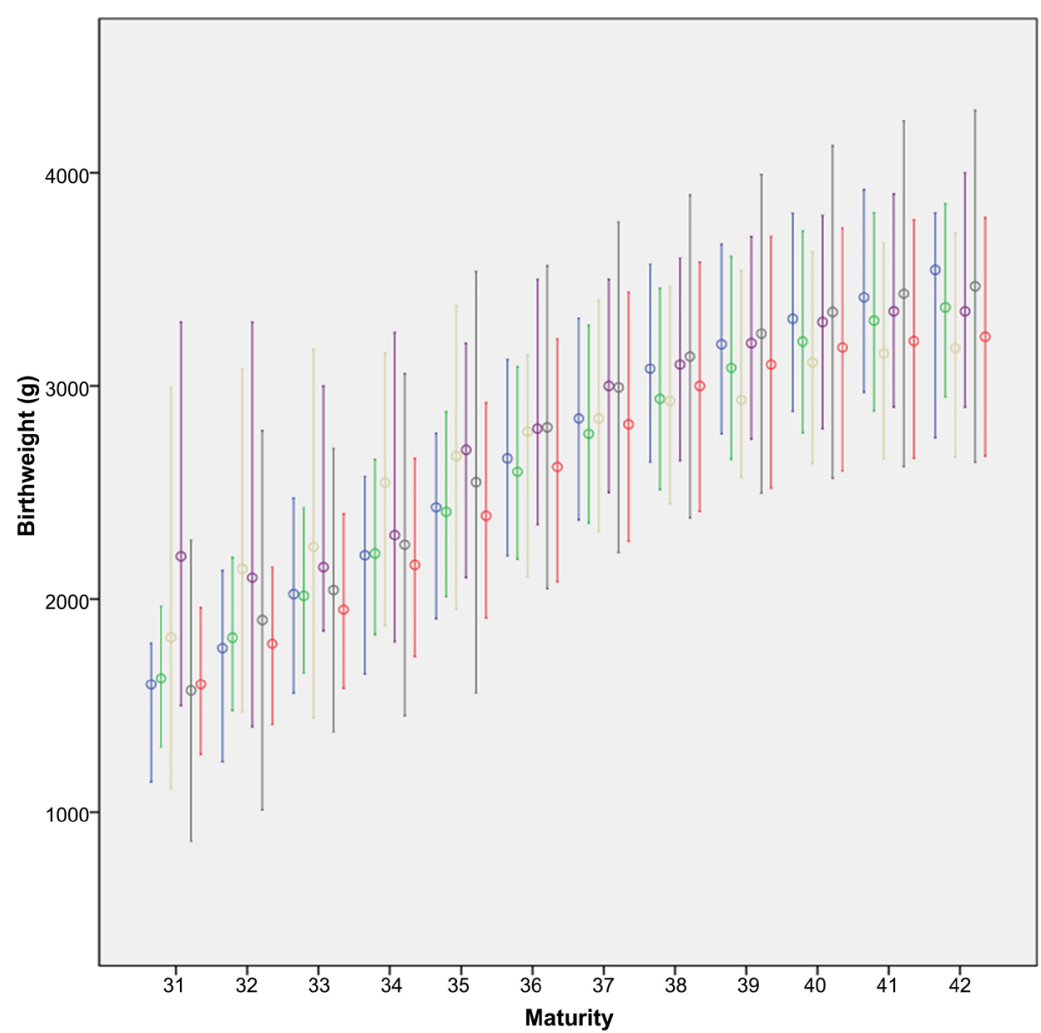

I UCH 10th-90th centile I Woo 10th-90th centilel Ip 10th- 90th centile

I Rogers 10 th-90th centilel

I Fok 2003 3rd-97th centilel

I Fok 1987 10th-90th centile

$\mathrm{OUCH}$ median

Woo median

Ip median

ORogers median

Fok 2003 median

OFok 1987 median

Figure 1. Comparison of median birthweight and centiles against gestational age for the different local studies.

available and date discrepancies would be common, while the latter study had the smallest sample size at each gestational week and thus the widest fluctuations.

A comparison of the centile ranges of the different Chinese studies, including the Guangzhou study [20], the Taiwan national study [22] and the Chinese national study [19], as well as the international INTERGROWTH-21 [28] and WHO [29] fetal growth reference data also showed that these differ widely across different gestations (Figure 2). Using the pre-set definition of $<10$ th centile as SGA and >90th centile as LGA, when the birthweights between $32-42$ weeks gestation in the $\mathrm{UCH}$ cohort were re-categorized using the cut-off criteria of each of the other datasets, the proportion of cases that would be classified as SGA or LGA varied widely from the standard value of $10 \%$ across different gestations. The gestational range of $32-42$ weeks was selected as many datasets did not have sufficient data for earlier gestations. The Fok 2003 study [27] only provided cut-offs for the $3^{\text {rd }}$ and $97^{\text {th }}$ centile so the expected proportion for SGA or LGA would be $3 \%$. It could be seen that the proportion of babies that would be categorized as SGA or LGA also varied widely across different gestations according to the reference centiles of the different studies (Table 3). Comparing the Hong Kong studies, it could be seen that the Ip [23] and Woo [24] centiles would grossly under-estimate the SGA proportion as $3.3 \%$ and $6 \%$, and over-estimate the LGA proportion as $16.8 \%$ and $13.6 \%$ respectively, while the Fok 1987 [26] centiles 


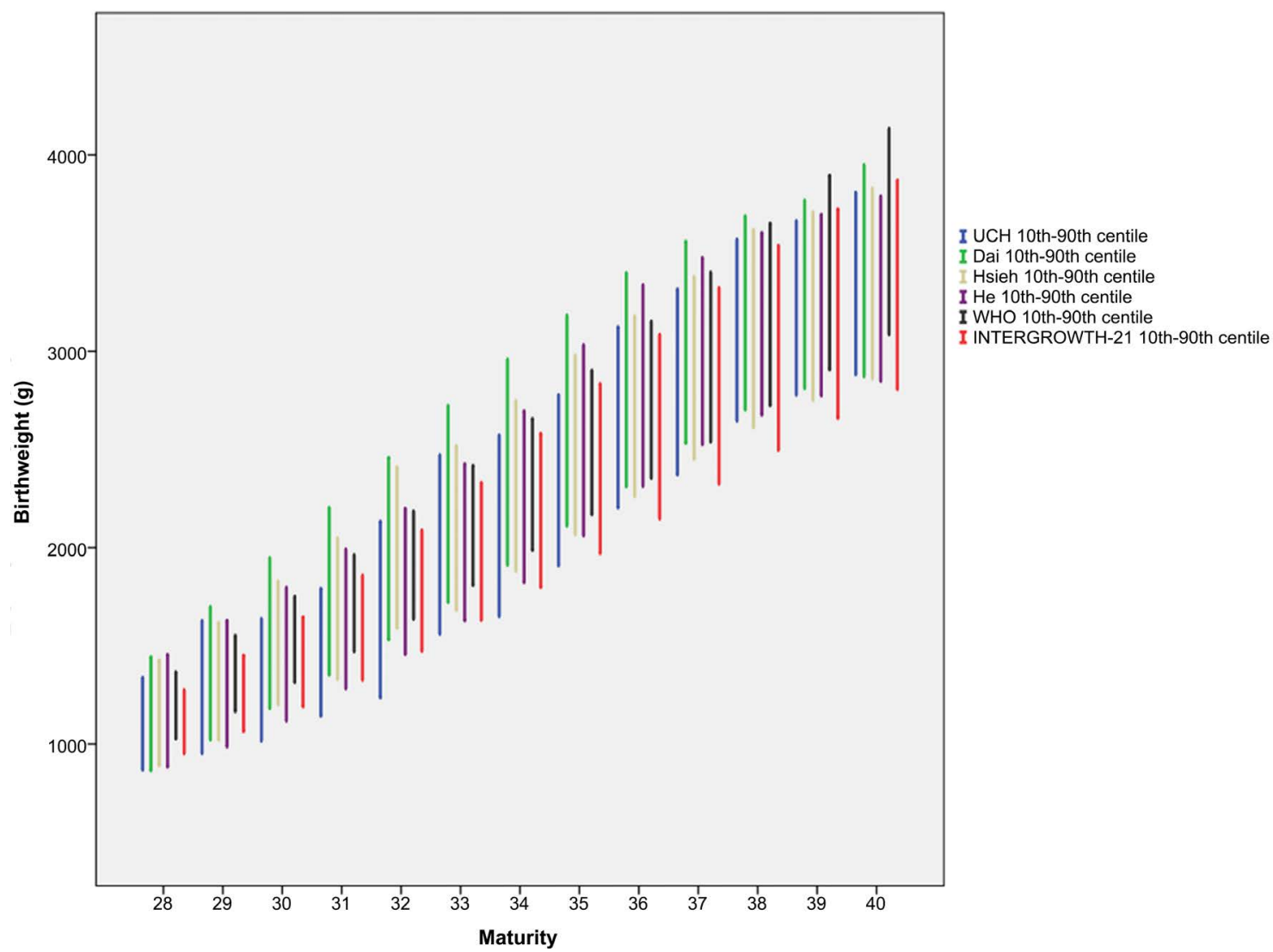

Figure 2. Comparison of centile ranges for various Chinese studies and the INTERGROWTH-21 and WHO reference curves.

Table 3. Percentage of births classified as small, appropriate or large for gestational age (SGA, AGA or LGA) according to the various charts for various gestations from $32-42$ weeks and for all births.

\begin{tabular}{|c|c|c|c|c|c|c|c|c|c|c|c|c|c|c|c|c|c|c|c|c|}
\hline \multirow[t]{2}{*}{ Weeks } & \multicolumn{2}{|c|}{ Ip } & \multicolumn{2}{|c|}{ Woo } & \multicolumn{2}{|c|}{ Rogers } & \multicolumn{2}{|c|}{ Fok 1987} & \multicolumn{2}{|c|}{ Fok $2003^{*}$} & \multicolumn{2}{|c|}{ Guongzhou } & \multicolumn{2}{|c|}{ Hsieh } & \multicolumn{2}{|c|}{ Dai } & \multicolumn{2}{|c|}{ WHO } & \multicolumn{2}{|c|}{ Intergrowth-21 } \\
\hline & SGA & LGA & SGA & LGA & SGA & SGA & SGA & LGA & SGA & LGA & SGA & LGA & SGA & LGA & SGA & LGA & SGA & LGA & SGA & LGA \\
\hline 32 & 25.3 & 0 & 25.3 & 6.7 & 20 & 21.3 & 0 & 0 & 20 & 9.3 & 21.3 & 5.3 & 32 & 0 & 28 & 0 & 33.3 & 6.7 & 25.3 & 12 \\
\hline 33 & 5.6 & 0 & 13.5 & 10.3 & 29.4 & 14.6 & 5.55 & 19.8 & 10.3 & 13.5 & 24.6 & 10.3 & 14.3 & 7.14 & 15.8 & 0.01 & 19.8 & 11.1 & 12.7 & 17.4 \\
\hline 34 & 21.2 & 0 & 19.9 & 6.4 & 17.3 & 18.6 & 3.2 & 0 & 14.7 & 6.4 & 18.6 & 5.76 & 21.1 & 4.48 & 21.8 & 0.01 & 26.3 & 6.41 & 16.7 & 9.6 \\
\hline 35 & 11.5 & 9.3 & 14.5 & 5.0 & 19.8 & 13.7 & 1.54 & 0 & 10.2 & 3.4 & 16.7 & 0.9 & 16.7 & 1.54 & 19.8 & 0 & 24.7 & 4 & 11.7 & 7.43 \\
\hline 36 & 7.3 & 9.4 & 9.2 & 12 & 19.8 & 12.7 & 5.6 & 1.48 & 6.76 & 6.6 & 15.6 & 4.12 & 12.3 & 8.41 & 15.5 & 3.4 & 19.8 & 9.4 & 8.25 & 12 \\
\hline 37 & 7.5 & 7.5 & 9.2 & 11.9 & 16 & 11.5 & 4.85 & 1.40 & 6.0 & 6.6 & 17.5 & 5.53 & 13 & 8.1 & 18.5 & 3.7 & 18.8 & 7.41 & 8.04 & 9.86 \\
\hline 38 & 3.0 & 15.3 & 4.7 & 15.5 & 10.5 & 11.6 & 1.75 & 2.18 & 2.38 & 9.62 & 11.5 & 8.78 & 8.33 & 8.26 & 13.3 & 5.84 & 14.6 & 7.29 & 4.26 & 11.5 \\
\hline 39 & 2.5 & 16.9 & 4.8 & 12.6 & 8.6 & 9.9 & 1.40 & 1.92 & 1.7 & 8.9 & 9.86 & 8.89 & 9.15 & 8.5 & 12.3 & 6.33 & 19.1 & 3.3 & 4.8 & 7.79 \\
\hline 40 & 2.0 & 20.1 & 5.7 & 13.8 & 6.4 & 8.3 & 1.32 & 2.46 & 1.7 & 13.2 & 8.32 & 10.8 & 9 & 9.29 & 9.76 & 5.26 & 25.4 & 2.37 & 6.56 & 7.57 \\
\hline 41 & 1.5 & 25.1 & 6.5 & 15.2 & 7.1 & 6.2 & 10.8 & 12.9 & 1.5 & 17.5 & 6.18 & 12.4 & 8.23 & 12.9 & 7.11 & 13.4 & - & - & - & - \\
\hline 42 & 4.2 & 29.2 & 20.8 & 4.2 & 20.8 & 12.5 & 4.16 & 0 & 4.2 & 12.5 & 12.2 & 4.1 & 20.8 & 4.1 & 20.8 & 0 & - & - & - & - \\
\hline Overall & 3.3 & 16.8 & 6.0 & 13.6 & 9.7 & 10.6 & 1.83 & 2.26 & 2.7 & 10.6 & 10.5 & 9.16 & 9.36 & 8.91 & 12.2 & 6.20 & 19.7 & 4.8 & 5.86 & 9.23 \\
\hline
\end{tabular}

Fok 2003 study only provided cut-offs for the $3^{\text {rd }}$ and $97^{\text {th }}$ centile, the expected proportion for SGA or LGA would be 3\%; while for the other studies, the expected proportion for SGA or LGA would be $10 \%$. Overall cut-offs approximating the expected proportions are shaded. 
would underestimate the of SGA proportion as $2.7 \%$ while giving the same LGA proportion as $10.6 \%$. Similarly, the Fok 2003 [27] 3rd and 97th centile cut-offs would underestimate the SGA proportion as $1.8 \%$ and the LGA proportion as $2.2 \%$ Only the Rogers study [25] centiles appeared applicable to our cohort, with around $9.7 \%$ and $10.6 \%$ being classified as SGA or LGA respectively. On the other hand, considering all gestations together, the Guangzhou study [20] and the Taiwan study [22] centiles apparently most closely resembled our own centiles. The two studies would classify around $10.5 \%$ and $9.36 \%$ of our cohort as SGA, and $9.16 \%$ and $8.91 \%$ as LGA respectively. Looking specifically at the term gestations of 38 - 42 weeks, the percentages that would be labelled as SGA and LGA continued to be reasonably close to the defined $10 \%$. On the contrary, both the INTERGROWTH-21 [28] and WHO [29] reference centiles did not apply well to our data, with the INTERGORWTH-21 under-estimating SGA as 5.86\% while giving a reasonable LGA rate of $9.23 \%$, while the WHO cut-offs grossly over-labelled $19.7 \%$ as SGA but under-diagnosed LGA as only $4.8 \%$.

\section{Discussion}

The characteristics of our study and its comparison with the previous studies of gestational age specific birthweight conducted in Hong Kong, the other Chinese studies and the international fetal growth references are summarized in Table 4. Among the different datasets, the Guangzhou [20] and the Taiwan [22] centiles apparently gave the best resemblance compared to our data.

Table 4. Comparison of the characteristics of the different studies.

\begin{tabular}{|c|c|c|c|c|c|c|}
\hline Author & $\begin{array}{c}\text { Year } \\
\text { published }\end{array}$ & Data years & Study population & $\mathrm{N}$ & $\begin{array}{l}\text { Available } \\
\text { Gestation }\end{array}$ & $\begin{array}{c}\text { Available } \\
\text { Cut-off centiles }\end{array}$ \\
\hline \multicolumn{7}{|c|}{ Retrospective birthweight data } \\
\hline Ip & 1978 & $1970-1972$ & HK Chinese & 16,836 & $28-44$ & $10-90$ \\
\hline Woo & 1986 & $1982-1984$ & HK Chinese & 15,815 & $28-42$ & $10-90$ \\
\hline Rogers & 1987 & 1984-1986 & HK Chinese & 8802 & $24-42$ & $5-95$ \\
\hline Fok & 1987 & $1982-1986$ & HK Chinese & 8445 & $27-42$ & $10-90$ \\
\hline Fok & 2003 & $1998-2001$ & HK Chinese & 10,339 & $24-42$ & $3-97$ \\
\hline Guangzhou & 2014 & $2007-2011$ & Guangzhou Chinese & 514,375 & $26-43$ & $3-97$ \\
\hline Hsieh & 2006 & $1998-2002$ & Taiwan Chinese & $1.29 \mathrm{M}$ & $22-44$ & $5-95$ \\
\hline Dai & 2014 & $2006-2010$ & Mainland Chinese & $1.1 \mathrm{M}$ & $28-44$ & $3-97$ \\
\hline \multicolumn{7}{|c|}{ Prospective USG estimated data } \\
\hline Intergrowth-21 & 2014 & 2009-2014 & 8 countries & 13,108 & $14-40$ & $3-97$ \\
\hline WHO & 2017 & 2014-2015 & 10 countries & 1387 & $14-40$ & $3-97$ \\
\hline $\begin{array}{l}\text { Present study } \\
\text { (Retrospective } \\
\text { birthweight data }\end{array}$ & & 2012-2017 & $\begin{array}{l}\text { Hong Kong } \\
\text { Chinese }\end{array}$ & 25,208 & $25-41$ & $3-97$ \\
\hline
\end{tabular}


The previously published Hong Kong studies were all based on retrospective birthweight cohorts. The Ip study [23] published almost five decades ago, represented the first local birthweight centiles in a university maternity hospital, while the Woo [24] and Rogers [25] birthweight centiles represented the growth standards of different regions of Hong Kong (Hong Kong Island and New Territories) in the 1980s respectively. Fok et al. prospectively updated his growth standards of Chinese newborns delivered in the 10 public hospitals and 2 private hospitals in 1990s [27] and attempted to include a more general overall representation of Hong Kong Chinese babies. Our study retrospectively constructed the birthweight references of Hong Kong Chinese babies within the past decade. While our database was based on a single public training hospital, there appears no good evidence that profound biological, ethnic or socioeconomic differences existed between different districts of Hong Kong that could generate sufficiently significant influence on birthweight. In the other hand, being a tertiary referral unit, our data included high risk pregnancies such as those born extremely preterm or with significant medical conditions, allowing the realistic spectrum of birthweights at each gestation to be included, rather than ideal growth centiles in a low risk normal cohort. Therefore, we believe that our data should still be a typical representation of the total local population of around 7 million in Hong Kong

Our study provides an updated local gestational age specific birthweight reference of Hong Kong Chinese newborns since the last published reference in 2003 [27]. Previous studies in China have shown that with changes in the socioeconomic factors and obstetric care, the average birthweight increased from $3186 \mathrm{~g}$ in 1993 to $3300 \mathrm{~g}$ in 2008 [30]. We did not observe a consistent increase in birthweight from the available studies over the past few decades. The birthweight statistics from the department of Health of Hong Kong also showed that the mean birthweight of Hong Kong newborns was $3.10 \mathrm{~kg}$ in 2016, which was similar to that of $3.19 \mathrm{~kg}$ in 1993 [31]. As Hong Kong people adopted a western living style, we may expect a local increase towards higher maternal obesity and pregnancy body mass index in recent years as in the Western societies [32] and thus higher birthweight. However, overweight and obesity had not been rising among an HK Chinese pregnant cohort from 1995 to 2005 [33], while social affluence may be associated with advanced maternal age or primiparous mothers of increasing age, which may contribute to obstetric complications like pre-eclampsia and lower birthweight [34]. These factors may counterbalance one another and result in a fairly similar birthweight in our study when compared with previous studies.

SGA and LGA are commonly used to define high risk groups of infants who are at increased risks of perinatal morbidity or mortality and therefore require additional antenatal surveillance. We observed a great difference when we applied the centile cut-offs of other studies to our cohort in the classification of SGA and LGA infants. The under-estimation of SGA using the older local birthweight percentiles might lead to under-diagnosis of fetal growth restriction 
in the antenatal period, leading to insufficient antenatal surveillance for such high-risk pregnancies, and the potential increased risks of perinatal adverse outcome. The over-classification of LGA also implied that AGA infants could be mis-targeted for extra intervention. On the other hand, true LGA infants would be overlooked. We found that the Guangzhou and the Taiwan birthweight centiles most closely resembled our cohort in terms of the cut-offs of SGA and LGA despite the absolute differences in the median or mean birthweights, particularly between 37 - 41 weeks. Presumably, both the Guangzhou and the Taiwan cohort were based on predominantly southern Chinese ethnicity cohorts within the past two decades. The close geographical as well as socioeconomic proximity would explain the close similarities between their cohort and our data.

When comparing the birthweight centiles between studies, the results can be affected by the heterogenous study methodology such as methods of data collection or statistical treatment of data in addition to sample size variations. Different studies calculated the birthweight or the gestational age differently. Rogers [25] rounded the birthweights to the nearest $50 \mathrm{~g}$, while Fok [27] measured the birthweights with accuracy to $5-10 \mathrm{~g}$. Some studies calculated the gestational age to the nearest weeks instead of the number of completed weeks, with or without the paediatric assessment of maturity after delivery. Moreover, different inclusion and exclusion criteria, such as stillbirths, major fetal congenital abnormalities, were used in different studies. Fok [26] excluded infants born to mothers with medical conditions or pregnancy complications in 1987 but included them in 2003 [27]. Although the effects should theoretically be balanced out with sufficiently large sample sizes, such heterogeneity could still incur errors in the prematurity groups with smaller numbers. In addition, many studies have attempted to produce reference birthweight percentile charts stratified by gender and parity, which are recognized predictors of birthweight. Some studies [24] [25] [26] making such distinctions showed that males babies were generally slightly heavier than female babies. Nulliparity was associated with a significantly increased risk of low birthweight (OR 1.41, 95\% CI 1.26, 1.58) and small for gestational age (OR 1.89, 95\% CI 1.82, 1.96) in a systemic review and meta-analyses [35]. However, growth curve charts that are specifically designed for male or female fetuses, or for women of different parity, are rarely in use in antenatal management. We have therefore decided not to attempt such stratifications when we presented growth centiles at each gestation.

While traditionally, growth charts in relation to gestation are created based on livebirth birthweight, ultrasound based estimations have recently also been introduced. While using birthweight references based on neonates born at various gestational ages represents the actual birthweight distribution, the possible bias that such preterm infants could more likely be growth restricted due to various antenatal pathology that predisposed to the preterm birth would always be present [36]. In addition, pragmatically there would be substantially fewer numbers of newborns for lower gestational ages, particularly with extremes of prematurity, making data particularly deficient at the ends of the curve. Therefore, 
ultrasound estimations of Intrauterine growth based on serial fetal biometry has been adovated in recent years to establish prospective fetal growth reference charts. However, the greatest limitation of such prospective ultrasound based fetal growth estimations lies in the absence of a widely accepted formula for fetal weight estimations that could be applicable to all populations.

The INTERGROWTH-21st [28] and World Health Organization [29] recently developed intrauterine fetal growth charts by ultrasound estimated fetal weight across 8 and 10 countries respectively. INTERGROWTH-21st Fetal Growth Longitudinal Study is an international, multicenter, population-based project conducted between 2009 and 2014 in eight urban areas including a suburban district of the Beijing municipality, China [37]. However, the accuracy of ultrasound estimated fetal weight is limited by different formulas used. We previously retrospectively compared the accuracy of different ultrasound formulas for fetal weight estimation and found that Hadlock1 was the most accurate with the lowest mean absolute percentage error 7.34 when compared with Shepard (9.00; $\mathrm{p}<0.001)$ and INTERGROWTH-21 (9.07; $\mathrm{p}<0.001)$, and the accuracy was significantly lower in fetuses with macrosomia and intrauterine growth restriction [38]. The data from our current cohort showed that the WHO data would grossly over-diagnose SGA and under diagnose LGA, while the INTERGROWTH reference would significantly underdiagnose SGA. Such findings were well supported by a recent local study of 970 fetuses with serial ultrasound growth data showing that the WHO centiles were consistently higher than our local centiles, while the INTERGROWTH-21 centiles were lower [39]. Similarly, a prospective cohort study demonstrated that a customized fetal growth standard detected more neonatal SGA compared with the INTERGROWTH-21st standard [40]. Ideally, customized fetal growth charts taking into account the parity, maternal height and weight and ethnicity could reflect adverse pregnancy outcome better [41]. We agree that the suitability of such international reference ranges for fetal growth would need to be evaluated and validated before being applied to any local population. Further research is required to demonstrate whether there are practical advantages in using ultrasound based growth charts as compared to birthweight derived data.

\section{Conclusion}

The use of previously published local birthweight centiles could lead to significant misclassifications of small and large for gestational age when applied to our contemporary cohort, implying the genuine need to update birthweight references for any local population. We have also found that significant discrepancies between the growth centiles from the new ultrasound based international references and our data, and further validation of the formulae used for birthweight estimation from these studies are needed. On the other hand, recent reference centiles from southern Chinese populations were apparently more in agreement with the centiles derived from our current cohort, giving support to the use of 
ethnically specific growth and birthweight references. Further comparisons with birthweight data from other populations should help to confirm such regional ethnic differences.

\section{Funding Statement}

The authors received no funding for support or completion of this study.

\section{Conflicts of Interest}

The authors declare they have no conflict of interest.

\section{References}

[1] Hon, K.L., Liu, S., Chow, J.C.Y., et al. (2018) Mortality and Morbidity of Extremely Low Birth Weight Infants in Hong Kong, 2010-2017: A Single-Centre Review. Hong Kong Medical Journal, 24, 460-465. https://doi.org/10.12809/hkmj177181

[2] Hanson, M.A. and Gluckman, P.D. (2014) Early Developmental Conditioning of Later Health and Disease: Physiology or Pathophysiology? Physiological Reviews, 94, 1027-1076. https://doi.org/10.1152/physrev.00029.2013

[3] Doctor, B.A., O’Riordan, M.A., Kirchner, H.L., Shah, D. and Hack, M. (2001) Perinatal Correlates and Neonatal Outcomes of Small for Gestational Age Infants Born at Term Gestation. American Journal of Obstetrics and Gynecology, 185, 652-659. https://doi.org/10.1067/mob.2001.116749

[4] Ye, J., Zhang, L., Chen, Y., Fang, F., Luo, Z. and Zhang, J. (2014) Searching for the Definition of Macrosomia through an Outcome-Based Approach. PLoS ONE, 9, e100192. https://doi.org/10.1371/journal.pone.0100192

[5] Cheng, Y.K.Y., Lao, T.T., Sahota, D.S., Leung, V.K.T. and Leung, T.Y. (2013) Use of Birth Weight Threshold for Macrosomia to Identify Fetuses at Risk of Shoulder Dystocia among Chinese Populations. International Journal of Gynecology \& $O b$ stetrics, 120, 249-253. https://doi.org/10.1016/j.ijgo.2012.10.019

[6] Lubchenco, L.O., Hansman, C., Dressler, M. and Boyd, E. (1963) Intrauterine Growth as Estimated from Liveborn Birth-Weight Data at 24 to 42 Weeks of Gestation. Pediatrics, 32, 793-800.

[7] Janssen, P.A., Thiessen, P., Klein, M.C., Whitfield, M.F., MacNab, Y.C. and Cullis-Kuhl, S.C. (2007) Standards for the Measurement of Birth Weight, Length and Head Circumference at Term in Neonates of European, Chinese and South Asian Ancestry. Open Medicine, 1, e74-e88.

[8] Hanley, G.E. and Janssen, P.A. (2012) Ethnicity-Specific Growth Distributions for Prediction of Newborn Morbidity. Journal of Obstetrics and Gynaecology Canada, 34, 826-829. https://doi.org/10.1016/S1701-2163(16)35380-4

[9] Hanley, G.E. and Janssen, P.A. (2013) Ethnicity-Specific Birthweight Distributions Improve Identification of Term Newborns at Risk for Short-Term Morbidity. American Journal of Obstetrics \& Gynecology, 209, 428.e1-6. https://doi.org/10.1016/j.ajog.2013.06.042

[10] Unterscheider, J., Geary, M.P., Daly, S., et al. (2013) The Customized Fetal Growth Potential: A Standard for Ireland. European Journal of Obstetrics \& Gynecology and Reproductive Biology, 166, 14-17. https://doi.org/10.1016/j.ejogrb.2012.09.007

[11] Sandra, B., James, C., Ron, G., Ian, G., Stephen, J. and Claire, W. (2008) Centile Charts for Birthweight for Gestational Age for Scottish Singleton Births. BMC 
Pregnancy and Childbirth, 8, 5. https://doi.org/10.1186/1471-2393-8-5

[12] Norris, T., Seaton, S.E., Manktelow, B.N., et al. (2018) Updated Birthweight Centiles for England and Wales. Archives of Disease in Childhood-Fetal and Neonatal Edition, 103, F577-F582. https://doi.org/10.1136/archdischild-2017-313452

[13] Olsen, I.E., Groveman, S.A., Lawson, M.L., Clark, R.H. and Zemel, B.S. (2010) New Intrauterine Growth Curves Based on United States Data. Pediatrics, 125, e214. https://doi.org/10.1542/peds.2009-0913

[14] Visser, G.H.A., Eilers, P.H.C., Elferink-Stinkens, P.M., Merkus, H.M.W.M. and Wit, J.M. (2009) New Dutch Reference Curves for Birthweight by Gestational Age. Early Human Development, 85, 737-744. https://doi.org/10.1016/j.earlhumdev.2009.09.008

[15] Terán, J.M., Varea, C., Bernis, C., Bogin, B. and González-González, A. (2017) New Birthweight Charts According to Parity and Type of Delivery for the Spanish Population. Gaceta Sanitaria, 31, 116-122. https://doi.org/10.1016/j.gaceta.2016.09.016

[16] Ozgul, S., Guner, K., Sinan, U., Emrah, C., Basak, B. and Asiye, N. (2012) New Intrauterine Growth Percentiles: A Hospital-Based Study in Istanbul, Turkey. Journal of Pakistan Medical Association, 62, 1070-1074.

[17] Itabashi, K., Miura, F., Uehara, R. and Nakamura, Y. (2014) New Japanese Neonatal Anthropometric Charts for Gestational Age at Birth. Pediatrics International, 56, 702-708. https://doi.org/10.1111/ped.12331

[18] Wen, S.W., Kramer, M.S. and Usher, R.H. (1995) Comparison of Birthweight Distributions between Chinese and Caucasian Infants. American Journal of Epidemiology, 141, 1177-1187. https://doi.org/10.1093/oxfordjournals.aje.a117391

[19] Dai, L., Deng, C., Li, Y., et al. (2014) Birth Weight Reference Percentiles for Chinese. PLoS ONE, 9, e104779. https://doi.org/10.1371/journal.pone.0104779

[20] He, J.R., Xia, H.M., Liu, Y., et al. (2014) A New Birthweight Reference in Guangzhou, Southern China, and Its Comparison with the Global Reference. Archives of Disease in Childhood, 99, 1091-1097. https://doi.org/10.1136/archdischild-2013-305923

[21] Liu, Z., Zhang, J., Zhao, B., et al. (2014) Population-Based Reference for Birthweight for Gestational Age in Northern China. Early Human Development, 90, 177-187. https://doi.org/10.1016/j.earlhumdev.2014.01.007

[22] Hsieh, W.S., Wu, H.C., Jeng, S.F., et al. (2006) Nationwide Singleton Birthweight Percentiles by Gestational Age in Taiwan, 1998-2002. Acta Paediatrica Taiwanica, 47, 25-33.

[23] Ip, H.M. (1978) Intrauterine Growth in Hong Kong Chinese. Biology of the Neonate, 33, 253-263. https://doi.org/10.1159/000241081

[24] Woo, J.S.K., Li, D.F.H. and Ma, H.K. (1986) Intrauterine Growth Standards for Hong Kong Chinese. The Australian and New Zealand Journal of Obstetrics and Gynaecology, 26, 54-58. https://doi.org/10.1111/j.1479-828X.1986.tb01529.X

[25] Rogers, M.S., Wong, F.W.S. and Chang, A.M.Z. (1987) Determinants of Birth-Weight in the New Territories of Hong Kong. The Australian and New Zealand Journal of Obstetrics and Gynaecology, 22, 314-319. https://doi.org/10.1111/j.1479-828X.1987.tb01017.x

[26] Fok, T.F., Lam, T.K., Lee, N., et al. (1987) A Prospective Study on the Intrauterine Growth of Hong Kong Chinese Babies. Biology of the Neonate, 51, 312-323. https://doi.org/10.1159/000242670

[27] Fok, T.F., So, H.K., Wong, E., et al. (2003) Updated Gestational Age Specific Birth- 
weight, Crown-Heel Length, and Head Circumference of Chinese Newborns. Archives of Disease in Childhood_Fetal and Neonatal Edition, 88, F229-F236. https://doi.org/10.1136/fn.88.3.F229

[28] Stirnemann, J., Villar, J., Salomon, L.J., et al. (2017) International Estimated Fetal Weight Standards of the INTERGROWTH-21st Project. Ultrasound in Obstetrics \& Gynecology, 49, 478-486. https://doi.org/10.1002/uog.17347

[29] Kiserud, T., Piaggio, G., Carroli, G., et al. (2017) The World Health Organization Fetal Growth Charts: A Multinational Longitudinal Study of Ultrasound Biometric Measurements and Estimated Fetal Weight. PLOS Medicine, 14, e1002220. https://doi.org/10.1371/journal.pmed.1002284

[30] Centre for Health Statistics and Information, Ministry of Health (2009) An Analysis Report of National Health Services Survey in China in 2008.

https://www.who.int/healthinfo/country monitoring_evaluation/China_CHeSS rep ort May 2009.pdf

[31] Summary Statistics on Birth Weight from the Department of Health, the Government of the Hong Kong Special Administrative Region. HealthyHK-Public Health Information and Statistics of Hong Kong-Birth Weight.

[32] Yeh, J. and Shelton, J.A. (2005) Increasing Prepregnancy Body Mass Index: Analysis of Trends and Contributing Variables. American Journal of Obstetrics and Gynecology, 193, 1994-1998. https://doi.org/10.1016/j.ajog.2005.05.001

[33] Leung, T., Leung, T., Sahota, D., et al. (2008) Trends in Maternal Obesity and Associated Risks of Adverse Pregnancy Outcomes in a Population of Chinese Women. BJOG, 115, 1529-1537. https://doi.org/10.1111/j.1471-0528.2008.01931.x

[34] Haines, C.J., Rogers, M.S. and Leung, D.H.Y. (1991) Neonatal Outcome and Its Relationship with Maternal Age. The Australian and New Zealand Journal of Obstetrics and Gynaecology, 31, 209-212.

https://doi.org/10.1111/j.1479-828X.1991.tb02782.x

[35] Shah, P.S. and Knowledge Synthesis Group on Determinants of LBW/PT Births (2010) Parity and Low Birthweight and Preterm Birth: A Systematic Review and Meta-Analyses. Acta Obstetricia et Gynecologica Scandinavica, 89, 862-875. https://doi.org/10.3109/00016349.2010.486827

[36] Gardosi, J.O. (2005) Prematurity and Fetal Growth Restriction. Early Human Development, 81, 43-49. https://doi.org/10.1016/j.earlhumdev.2004.10.015

[37] Papageorghiou, A.T., Ohuma, E.O., Altman, D.G., et al. (2014) International Standards for Fetal Growth Based on Serial Ultrasound Measurements: The Fetal Growth Longitudinal Study of the INTERGROWTH-21st Project. The Lancet, 384, 869-879. https://doi.org/10.1016/S0140-6736(14)61490-2

[38] Kong, C.W. and To, W.W.K. (2019) Comparison of the Accuracy of INTERGROWTH-21 Formula with Other Ultrasound Formulae in Fetal Weight Estimation. Taiwanese Journal of Obstetrics \& Gynecology, 58, 273-277.

[39] Cheng, Y.K.Y., Lu, J., Leung, T.Y., Chan, Y.M. and Sahota, D.S. (2018) Prospective Assessment of INTERVROWTH-21st and World Health Organization Estimated Fetal Weight Reference Curves. Ultrasound in Obstetrics \& Gynecology, 51, 792-798. https://doi.org/10.1002/uog.17514

[40] Odibo, A.O., Nwabuobi, C., Odibo, L., Leavitt, K., Obican, S. and Tuuli, M.G. (2018) Customized Fetal Growth Standard Compared with the INTERGROWTH-21st Century Standard at Predicting Small-for-Gestational-Age Neonates. Acta Obstetricia et Gynecologica Scandinavica, 97, 1381-1387. https://doi.org/10.1111/aogs.13394 
[41] Gardosi, J., Francis, A., Turner, S. and Williams, M. (2018) Customized Growth Charts: Rationale, Validation and Clinical Benefits. AJOG Expert Reviews. AJOG, 218, S609-S618. https://doi.org/10.1016/j.ajog.2017.12.011 